\title{
CEMENT BURN OF THE SCIATIC NERVE
}

\author{
R. BIRCH, M.C. P. WILKINSON, K. P. VIJAYAN, S. GSCHMEISSNER
}

From the Royal National Orthopaedic Hospital, Stanmore

\begin{abstract}
We present the case of a 63-year-old woman who sustained an acrylic cement burn of the sciatic nerve at hip replacement. She was treated by resection of the damaged segment and grafting. Electron microscopy showed that the nerve was nearly normal $1 \mathrm{~cm}$ from the cement margin indicating that this is a safe level for resection.
\end{abstract}

There are few reports of injury to major nerves from methylmethacrylate cement. We describe a case of a cement burn of the sciatic nerve, with causalgia and loss of function in the leg.

\section{CASE REPORT}

Right total hip arthroplasty was performed in a 63-yearold woman by the lateral approach, with osteotomy of the trochanter. Postoperatively, she was found to have a complete sciatic palsy with causalgia. She was unable to sit, sleep was disturbed and the pain was described as intense and burning, with severe 'pins and needles'. Nerve conduction studies confirmed a degenerative nerve lesion. Treatment in a pain clinic did not relieve her symptoms.

She was referred to the Royal National Orthopaedic Hospital at 16 months with persisting severe burning pain, extreme tenderness in the buttock and little evidence of recovery in the nerve. The leg was blue, swollen and cold, and there were trophic changes in the nails and skin of the foot. The arterial pulses were all palpable. Radiographs of the hip showed the prosthesis in a satisfactory position with sound union of the trochanteric osteotomy.

At operation the sciatic nerve was found to be embedded in cement which had extruded from the

R. Birch, MChir, FRCS, Consultant Orthopaedic Surgeon M. C. P. Wilkinson, FRCS, Orthopaedic Registrar

K. P. Vijayan, DOrth, MSc(Orth), Senior House Officer

Royal National Orthopaedic Hospital Trust, Brockley Hill, Stanmore, Middlesex HA7 4LP, England.

S. Gschmeissner, BSc, FIMLS, Chief Scientific Officer

Electron Microscopy Unit, Imperial Cancer Research Fund, PO Box

123, Lincoln's Inn Fields, London WC2A 3PX, England.

Correspondence should be sent to Mr R. Birch.

(C) 1992 British Editorial Society of Bone and Joint Surgery $0301-620 \mathrm{X} / 92 / 5440 \$ 2.00$

J Bone Joint Surg [ Br] 1992; 74-B:731-3.

posterior acetabulum (Fig. 1). Only two bundles of the lateral division of the nerve appeared to be intact and were conducting. The remainder of the nerve was resected and the $7 \mathrm{~cm}$ gap was bridged by sural nerve grafts.

Biopsies from the proximal and distal stumps of the divided nerve confirmed satisfactory morphology proximally and the expected degenerative changes distally.

The immediate relief of pain was substantial. The burning sensation and the severe local tenderness in the buttock disappeared three weeks after the operation, but painful 'pins and needles' in the leg and foot persisted. At 21 months after the nerve grafting the patient was able to walk with an ankle-foot orthosis and two sticks.

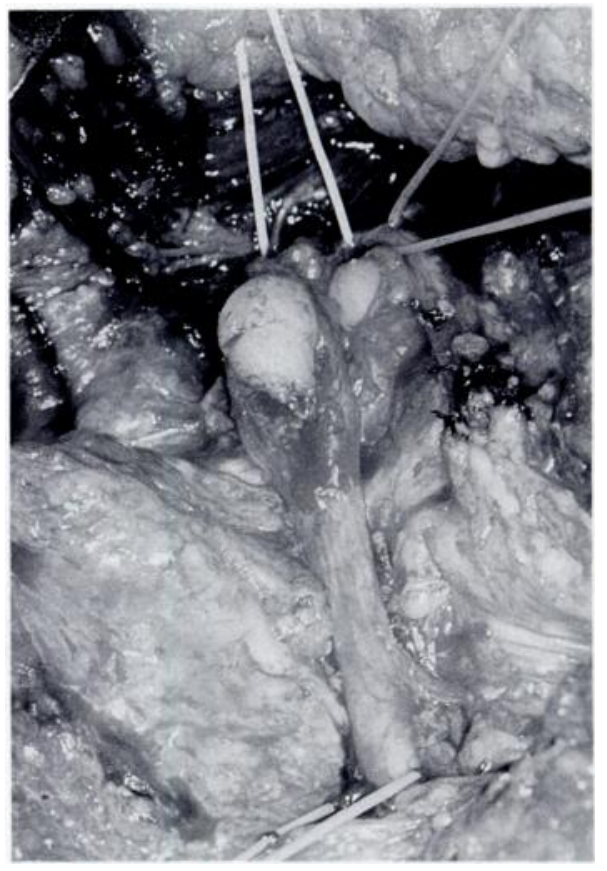

Fig. 1

Sciatic nerve embedded in cement which had extruded from the acetabulum during total hip replacement. 


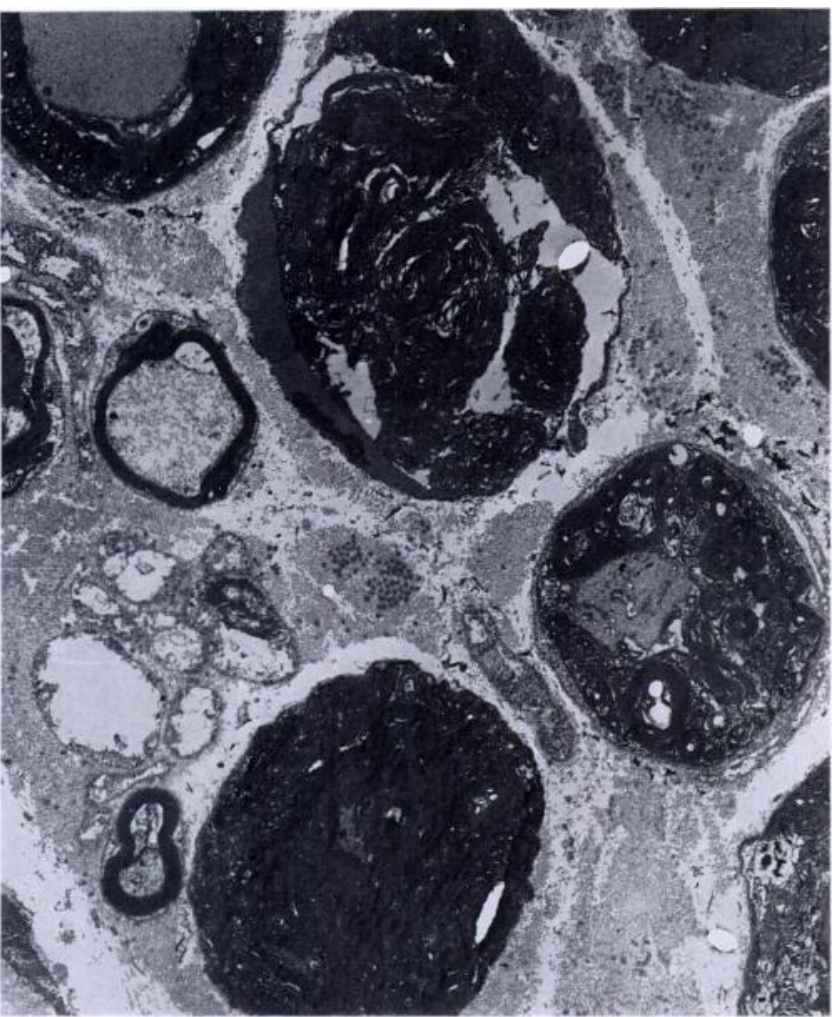

Fig. 2a

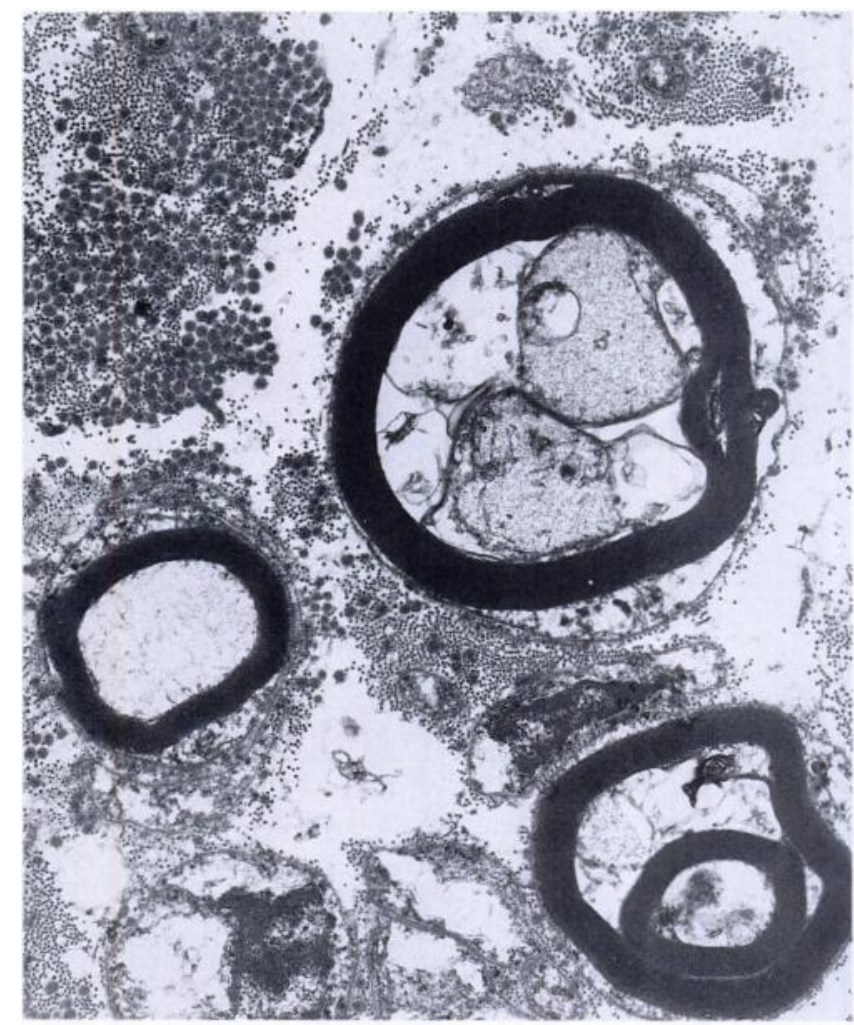

Fig. 2b

Electron microscopy of the median nerve at the cement margin. Figure $2 \mathrm{a}$ - The axoplasm is destroyed, the myelin is disrupted and some of it is liquefied $(\times 2500)$. Figure $2 b-$ The basement membranes are lifted away from the Schwann-cell processes and there is coagulation of endoneural collagen $(\times 7000)$.

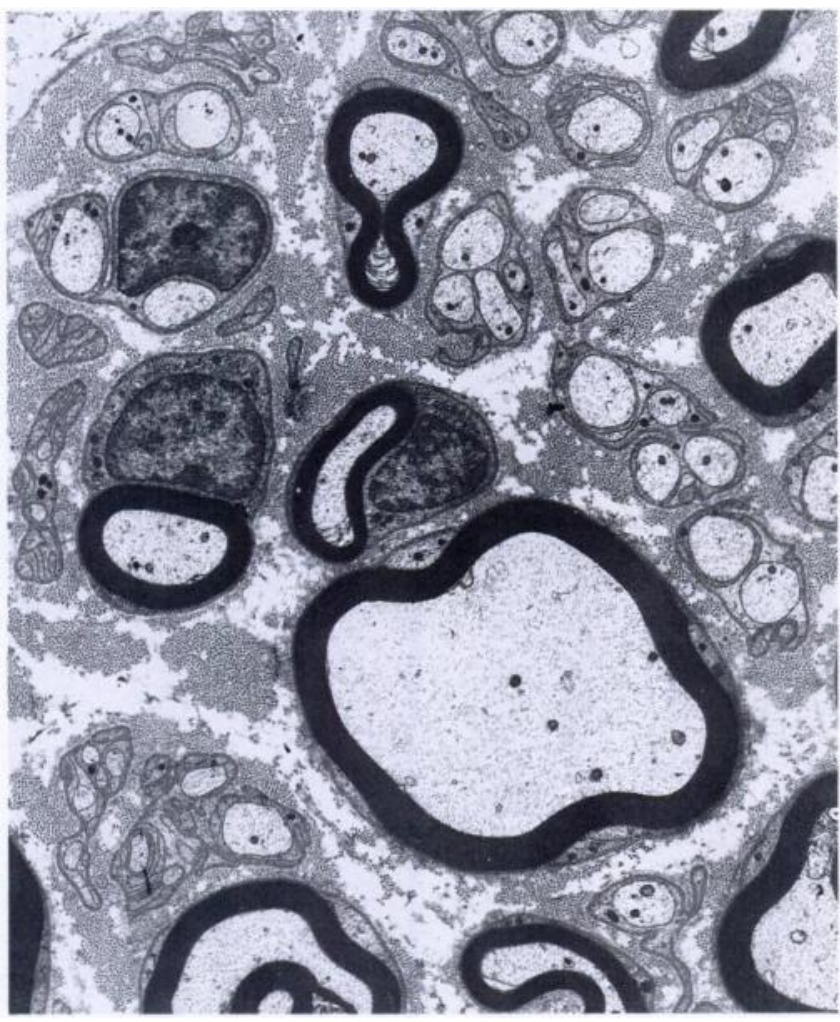

Fig. 3a

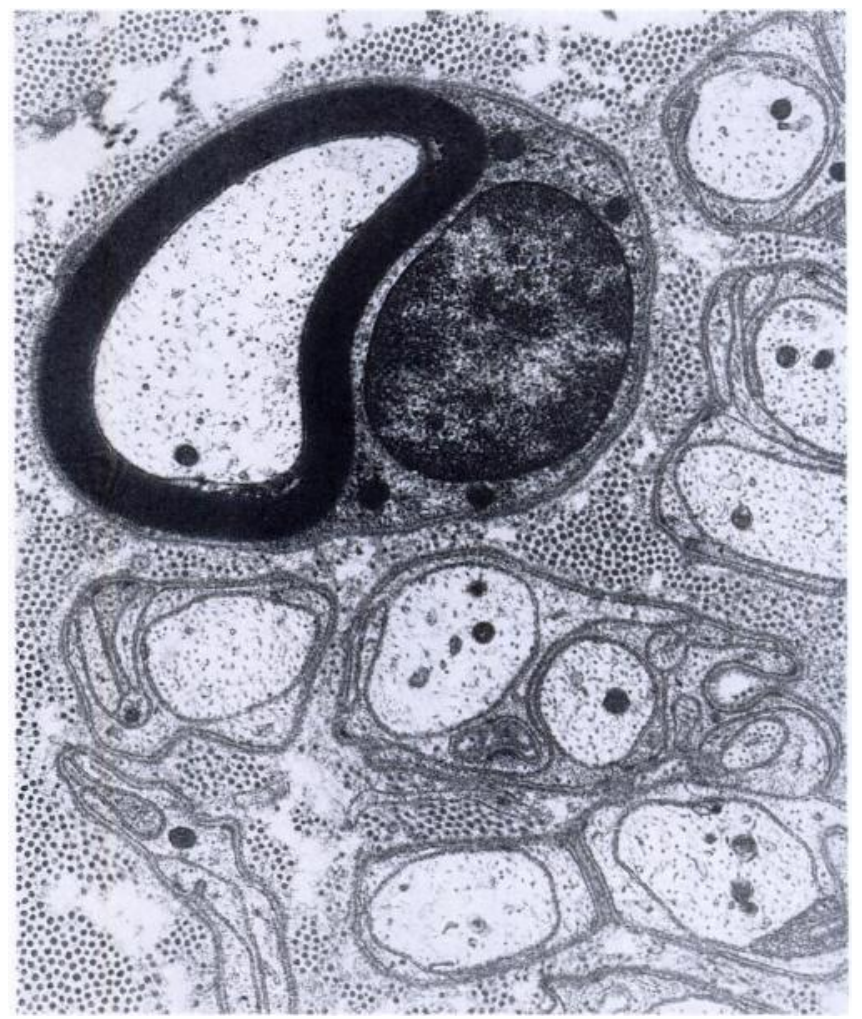

Fig. 3b

Electron microscopy of the median nerve $10 \mathrm{~mm}$ from the cement margin. Figure $3 \mathrm{a}-\mathrm{A}$ normal pattern of myelinated and non-myelinated nerve fibres is seen $(\times 4350)$. Figure $3 \mathrm{~b}-$ Myelinated and non-myelinated nerve fibres, basement membrane, Schwann cytoplasm and endoneural collagen all appear normal $(\times 14000)$. 
The medial hamstrings had recovered to MRC grade 4, and the flexor muscles of the ankle to MRC grade 3 . The foot remained cold, discoloured and swollen.

\section{EXPERIMENTAL STUDY}

A patient with a complete pre-ganglionic injury of the brachial plexus elected for amputation of the afflicted arm 15 months after his accident. Sensory potentials were recorded from the median and ulnar nerves before operation. Within five minutes of amputation, the median nerve was exposed in the arm and was embedded in Simplex cement (Howmedica, London, England). The epineural vessels were seen to thrombose up to $5 \mathrm{~mm}$ from the cement margin and the nerve within the cement became charred. Biopsies were taken from the nerve adjacent to the cement and at 5,10 and $20 \mathrm{~mm}$ intervals proximally and distally to it. Electron microscopy showed normal histological appearances at the 10 and $20 \mathrm{~mm}$ intervals (Figs 2 and 3).

\section{DISCUSSION}

Cold injuries to nerves have been well described. DennyBrown et al (1945) showed that severe cold caused degeneration of axons but no disruption of the connectivetissue sheaths within the nerve, so that regeneration was possible. Seddon (1975), Thomas and Holdorff (1984) and Sunderland (1990) extensively reviewed the published work on cold injury but found no information which materially altered these conclusions.

Little has been written about thermal injuries. Dale (1954) and DiVincenti, Moncreif and Pruitt (1969) discussed electrical burns and showed how serious these were because of extensive muscle necrosis. In some of their cases, nerves passing through the infarcted mass appeared to be intact. Wilkinson and Clarke (1992) describe two cases of burns of the brachial plexus in unconscious patients from domestic radiators. The limbs were exposed to heat for several hours, causing fullthickness skin burns. The underlying nerves were also burned and limited recovery followed in only one patient.

Simplex cement reaches a temperature of $95^{\circ} \mathrm{C} 15$ minutes after mixing and stays at above $70^{\circ}$ for 12 minutes (Bonney, personal communication, 1990). It is perhaps surprising that there are so few reports of injury to major nerve trunks from cement. Ratliff (1984) collected 50 cases of nerve injury after total hip replacement, the most detailed and the largest series yet published, but found no example of direct injury to a nerve from cement. Casagrande and Danahy (1971) described a case of late-onset sciatic palsy after arthroplasty of the hip. The symptoms developed seven months after the operation and when the sciatic nerve was explored it was found to be scarred as it passed close to extruded cement. Coventry et al (1974) found only one case of nerve injury in over 2000 arthroplasties of the hip. Weber, Daube and Coventry (1976) found two cases of cement injury, both to the femoral nerve. There was limited recovery in one of these cases. Siliski and Scott (1985) reported four cases of cement injury to the obturator nerve after perforation of the medial wall of the pelvis. They explored three nerves and found one encased in cement, one partially surrounded, and one adjacent to cement.

In cement burns, unlike electrical burns, the extent of injury to the nerve is limited. In our case resection of the nerve to $1 \mathrm{~cm}$ from either side of the cement revealed healthy nerve stumps and grafting mitigated pain and improved function.

The authors do not wish to respond to the request for a conflict of interest statement.

\section{REFERENCES}

Casagrande PA, Danahy PR. Delayed sciatic nerve entrapment following the use of self curing acrylic: a case report. J Bone Joint Surg [Am] 1971; 53-A :167-9.

Coventry MB, Beckenbaugh RD, Nolan DR, Ilstrup DM. 2,012 total hip arthroplasties: a study of postoperative course and early complications. J Bone Joint Surg [Am] 1974; 56-A :273-84.

Dale RH. Electrical accidents: a discussion with illustrative cases. $B r J$ Plast Surg 1954; 7:44-66.

Denny-Brown DE, Adams RD, Brenner C, Doherty MM. The pathology of injury to nerve induced by cold. J Neuropath Exp Neurol 1945; 4:305-23.

DiVincenti FC, Moncreif JA, Pruitt BA. Electrical injuries: a review of 65 cases. J Trauma 1969; 9:497-507.

Ratliff AHC. Vascular and neurological complications. In : Ling RSM, ed. Complications of total hip replacement. (Current problems in orthopaedics). Edinburgh, etc: Churchill Livingstone, 1984:18-29.

Seddon H. Surgical disorders of the peripheral nerves. Second ed. Edinburgh, etc: Churchill Livingstone, 1975.

Siliski JM, Scott RD. Obturator nerve palsy resulting from intrapelvic extrusion of cement during total hip replacement: report of four cases. J Bone Joint Surg [Am] 1985; 67-A :1225-8.

Sunderland S. Nerve injuries and repair. Edinburgh, etc: Churchill Livingstone, 1990.

Thomas PK, Holdorf B. Neuropathy due to physical agents. In : Dyck PJ, Thomas PK, Lambert EH, Burnge R, eds. Peripheral neuropathy. Second ed, Vol II. Philadelphia, etc: W. B. Saunders, 1984:1479-1511.

Weber ER, Daube JR, Coventry MB. Peripheral neuropathies associated with total hip arthroplasty. J Bone Joint Surg [Am] 1976; 58-A: 66-9.

Wilkinson MCP, Clarke JA. Burns to the brachial plexus. Injury 1992; $23: 342-3$ 